\title{
A study of relative permeability parameters on rock cores using a two-phase flow test
}

\author{
Chung-Hui Chiao, ${ }^{1,2}$, Chi-Wen $\mathrm{Yu}^{3, *}$, Shih-Chang Lei ${ }^{3}$, Jyun-Yu Lin ${ }^{2}$, and Chia-Yu Lu ${ }^{1}$ \\ ${ }^{I}$ Department of Geosciences, National Taiwan University, Taipei City, Taiwan \\ ${ }^{2}$ Taiwan Power Company, Taipei City, Taiwan \\ ${ }^{3}$ Sinotech Engineering Consultants Inc., Taipei City, Taiwan
}

\section{Article history: \\ Received 21 March 2012 \\ Revised 10 September 2012 \\ Accepted 1 August 2013}

Keywords:

Geo-sequestration, Two-phase flow, Relative permeability, K-S curve, History matching

\section{Citation:}

Chiao, C.-H., C.-W. Yu, S.-C. Lei, J.Y. Lin, and C.-Y. Lu, 2017: A study of relative permeability parameters on rock cores using a two-phase flow test. Terr. Atmos. Ocean. Sci., 28, 177-192, doi: 10.3319/ TAO.2013.08.01.01(GSC)

\begin{abstract}
To ensure sequestration safety, confirming the injectivity of the reservoir rock formation is of critical importance, requiring studies of the rock permeability to uncover the fluid migration scenarios within the porous reservoir rock. Two-phase (super-critical $\mathrm{CO}_{2}$-brine) flow behavior following the post $\mathrm{CO}_{2}$ injection is believed to be a dominating factor; its flooding behavior within the porous rock media needs to be further clarified prior to confirming the feasibility of domestic $\mathrm{CO}_{2}$ geo-sequestration. This study aims to determine the relative permeability of rock cores obtained from field outcropping. A test facility was established to determine the relative permeability during drainage and imbibition processes using a core-flooding test characterized by displacement method. The test facility was assembled locally and is regarded as a pioneering attempt. By relevant data interpretation, the parameters of relative permeability for predicting the movement of super-critical $\mathrm{CO}_{2}$ after injection can be modeled. More reliable parameters can be obtained using history matching processes wherein time-elapsed data calibration is used in conjunction with a computer code, TOUGH 2 . The test results were iteratively calibrated using numerical simulation by conducting a history matching process. The $K-S$ curves derived from best-fit parameters are believed to be the most relevant relative permeability for the reservoir rock. Through this preliminary study, a better understanding of some of the problems and limitations associated with the determination of the rock relative permeability using two-phase flow test is achieved, but more advanced research is required.
\end{abstract}

\section{INTRODUCTION}

Anthropogenic carbon emissions have long been recognized as a critical factor contributing to global warming (IPCC 2005). Large-scale geo-sequestration of carbon dioxide derived from coal-fired power plants has been identified as a major abatement technology, which may significantly reduce carbon emissions and mitigate the global warming (Yu et al. 2011). A deep saline aquifer where its depth is in excess of $800 \mathrm{~m}$ theoretically may be suitable for serving as a geo-sequestration reservoir. However, the injectivity and stability of the reservoir rock have to be confirmed in advance. Some effort have been made, thus far, to study rock porosity and permeability to uncover the fluid migration scenarios, short or long term, in the tiny voids within

\footnotetext{
* Corresponding author

E-mail:yu1014@sinotech.org.tw
}

the reservoir rock. Among those, two-phase $\left(\mathrm{CO}_{2}\right.$-brine water) flow behavior immediately following the post injection stage is believed to be a dominating factor (Benson et al. 2005). The $\mathrm{CO}_{2}$-brine reaction mechanism, however, still needs to be further clarified.

Two-phase flow in porous reservoir rock media like sandstone involves a drainage process where a super-critical phase $\mathrm{CO}_{2}$ (non-wetting phase) intrudes into rock voids filled with pre-existing briny water (wetting phase). The intruding $\mathrm{CO}_{2}$ will then replace the briny water assuming sufficient pressure is used to drain the water. Due to the lower density of super-critical $\mathrm{CO}_{2}$ than that of water, the $\mathrm{CO}_{2}$ will then move upwards in the reservoir by the buoyancy effect (Silin et al. 2009), which may be accompanied with an imbibition process leading to a residual trapping condition within the reservoir. 
The injection pressure will be one of the major controlling factors for the drainage process. The pressure must be high enough to overcome the capillary pressure and drain the water away but low enough to prevent an uncontrolled hydraulic fracturing, which might induce unwanted leakage.

In order to better understand, the drainage process for evaluating the feasibility of a domestic $\mathrm{CO}_{2}$ geo-sequestration, the behavior of the two-phase flow is studied using core-flooding test implemented by the displacement method (Qadeer et al. 2002; Bennion and Bachu 2005; Suenaga and Nakagawa 2011; Kameya et al. 2011). The sandstone cores were obtained from an outcrop by a shallow drilling machine with a NQ-size sampler, which can acquire undisturbed rock specimens at a depth less than $30 \mathrm{~m}$. A test facility was assembled by the authors' team locally and is regarded as a pioneering attempt. This paper presents the results of the study, including the data acquired, curve fitting by an empirical formula, and fitting parameters for representing the relative permeability.

\section{CORE SAMPLING}

In the early phases of carbon geo-sequestration development, deep-seated rock cores were not available until after a characteristically expensive deep well was deployed. To obtain a basic understanding of rock behavior under twophase flow conditions, typical rock samples from a candidate reservoir are preferable to full-scale on-site research. Figure 1 shows the drilling and core sampling location. Four shallow drillings including TP-01, TP-02, TP-03, and TP04 were developed at a depth of up to $50 \mathrm{~m}$ for each. The homogeneous sandstone in TP-04 has been selected for this study and is sampled from a rock formation of the Early Pleistocene to Upper Pliocene, locally named the Toukoshan Formation. The sampled cores for testing are believed to belong to the lower part of Toukoshan Formation where a sandy deposition prevailed during the fast sedimentation which formed the Foreland Basin in the western flank of an early sedimentary basin of western Taiwan (Lin et al. 2003; Teng and Lin 2004). The geological process has been found to have a strong connection to the latest orogeny episode several million years ago where a plate-collision center existed in the central part of the island of Taiwan. The rock formation in an outcrop which shows an excellent exposure of the sandstone with shale alternation is shown in Fig. 2.

\section{CORE TESTING}

The core specimen, immediately after being taken from the sampler, was covered with a heat-shrinkable film (membrane). Stabilized by bi-crescent rigid plates and transported back to the laboratory.

\subsection{Test Apparatus}

Figure 3 shows the two-phase test facility used for this study. It has been designed and constructed by the research team consisting mainly from the staff from the Taiwan Power Company and Sinotech Engineering Consultants, Inc.

The layout of major elements is illustrated in Fig. 4. The major elements consist of (a) 3 syringe pumps and 1 cell pressure control pump, (b) tri-axial high pressure chamber, (c) volume change meter (two-phase fluid separator), (d) incubator, (e) real-time monitor system, and (f) data logging system. This core-flooding test facility is designed as an unsteady-state or displacement type testing approach. It has been designed to be able to maintain the $\mathrm{CO}_{2}$ phase condition beyond a critical point, e.g., 7.4 MPa (pressure) and $31^{\circ} \mathrm{C}$ (temperature). To simplify the two-phase flow process, highly concentrated $\mathrm{CO}_{2}(99.5 \%)$ and distilled water instead of briny water was used. A sophisticated density difference two-phase fluid separator which allows precise measurement of the rate of gas outflow and water drainage from the core system in real time was carefully designed and used in the test.

The benefits of using the displacement or steady state method have been widely discussed (Qadeer et al. 2002; Perrin et al. 2009; Suenaga and Nakagawa 2011). The reasons for selecting the displacement method in this study is not only to take into account the cost and time involved in a steady-state method, but also to consider an easier reliability check in conjunction with other research teams in Japan, OYO Corporation (Kameya et al. 2011), and CRIEPI (Suenaga and Nakagawa 2011).

When using the steady-state method (Perrin et al. 2009, 2011), combinations of different proportions of $\mathrm{CO}_{2}$ and water are injected into a pressurized rock core specimen under a constant flow rate until a steady state two-phase flow condition is reached. The induced pressure and stable flow rate against the water saturation $\left(S_{w}\right)$ are then recorded. Since the fluid injection rate at the inlet will eventually equal the outflow rate at the outlet allowing fluid permeability to be calculated directly by virtue of Darcy's law.

Due to the fact that a relatively prolonged time is needed in reaching a steady state flow condition involved in a steady-state test, the displacement method is noted as a much more efficient test method apart from its drawbacks in the complexity involved in test data processing procedures. Different from the steady state test, only the transient state of flow behavior can be obtained during the displacement test, and thereby, a series of sophisticated calculation procedures must be exercised in order to obtain realistic results resembling a steady state flow condition. Moreover, highly accurate test monitoring data, including differential pressure change, and outflow water and gas (super critical $\mathrm{CO}_{2}$ ) volume, are necessary to achieve high quality test data processing and interpretation.

It has been noted by Kameya et al. (2011) that in a displacement type core flooding test, both the saturation 
and pressure change rapidly near the outflow surface. This phenomenon is caused by a discontinuous change of capillary pressure across outflow surface and is usually called a capillary end effect. To reduce the capillary end effect, the flow rate must be sufficiently high. Toth et al. (2001) emphasized that the capillary end-effects will normally affect the measurement accuracy both in a displacement method and a steady state method; however, the effect can be minimized if the injection rate can be increased to some extent in a displacement method. By mercury-injection capillary pressure tests conducted on rock samples, Bennion and Bachu (2006) depicted the impact of interfacial tension and poresize distribution/capillary pressure characteristics on relative permeability with regard to $\mathrm{CO}_{2}$ within reservoir conditions

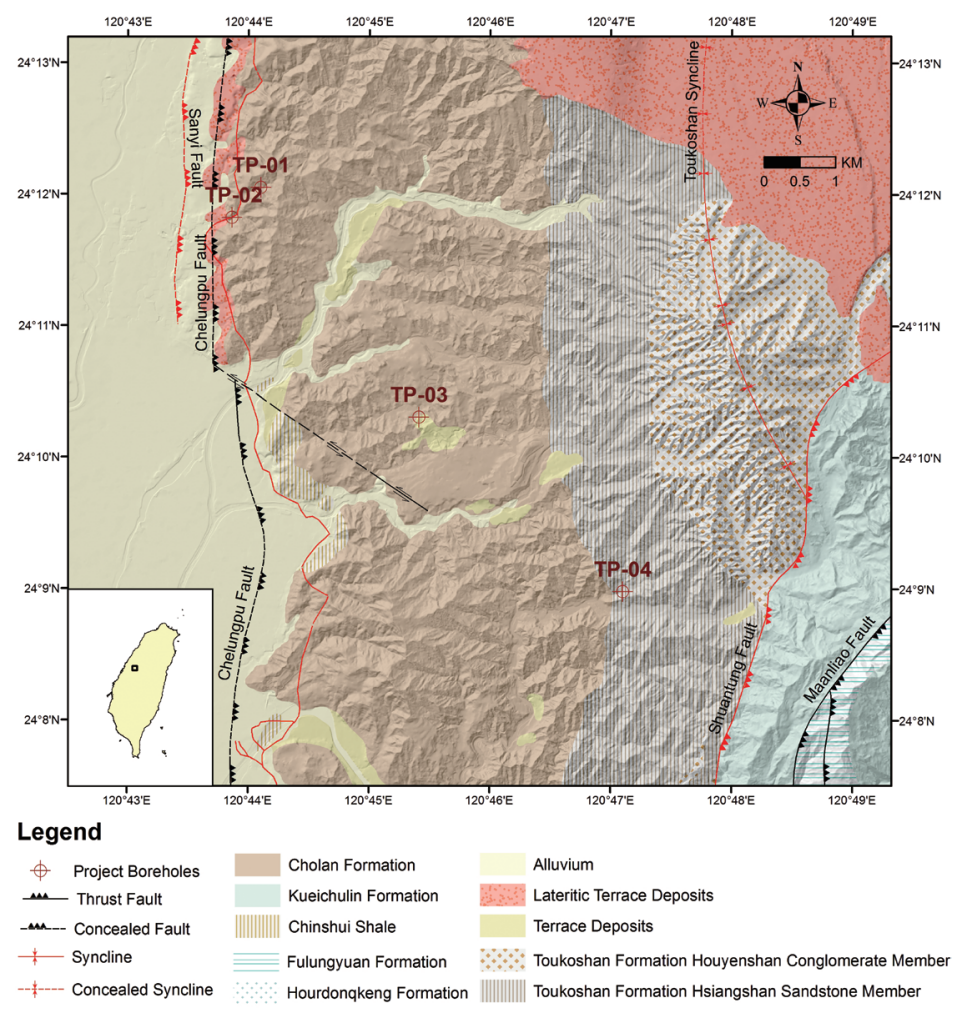

(Modified from the 1:50000 scale Geological Map producted by Central Geological Survey, Taiwan)

Fig. 1. Geological plan showing the drilling and core sampling locations, boreholes no. TP-01 and TP-02 for sampling cores from the Chinshui shale or uppermost part of Kueichulin formation; while boreholes no. TP-03 and TP-04 aimed at sampling core from above younger formations including the Cholan and Hsiangshan sandstone member of the Toukoshan formation. The background geological map has been modified from the digital version geological map (scale of 1:50000) that was provided by the Central Geological Survey of Taiwan.

(a)

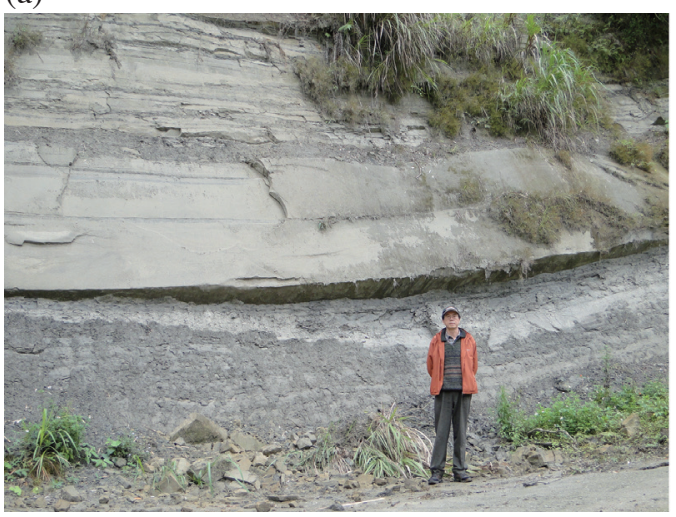

(b)

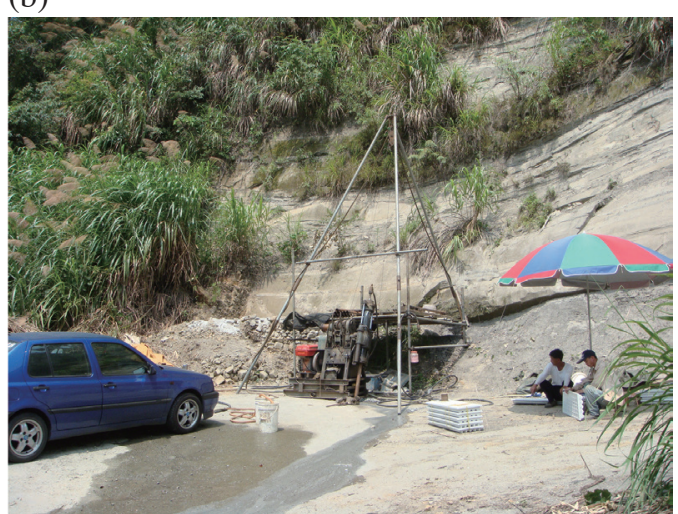

Fig. 2. Rock outcrop near boreholes no. TP-04 and TP-04H: (a) the rock stratum with the same height of the person is sandstone with shale alternation, while the stratum above is a homogeneous sandstone layer, (b) drilling to take vertical core sample. 


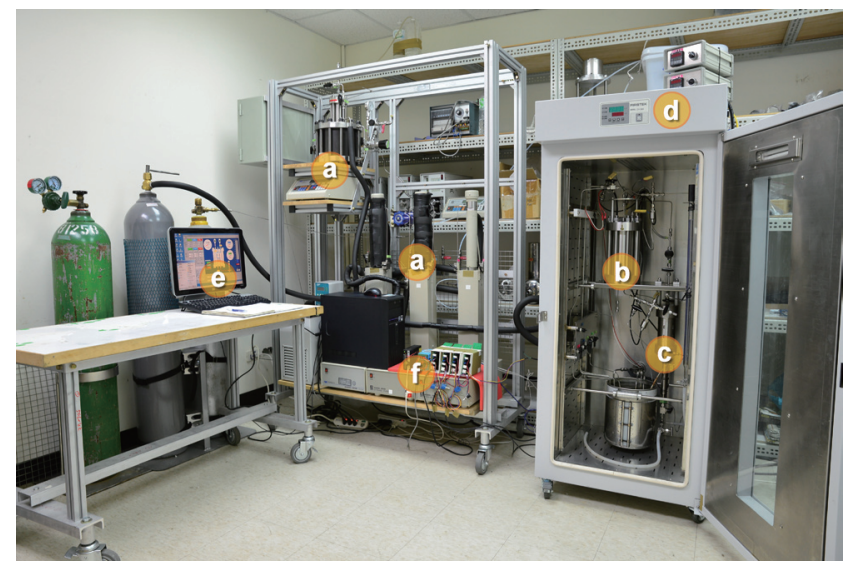

Fig. 3. Two-phase test facility - Displacement method. The major elements consist of (a) the 3 syringe pumps and 1 cell pressure control pump, (b) tri-axial high pressure chamber, (c) volume change meter, (d) incubator, (e) real-time monitor system, and (f) data logging system.

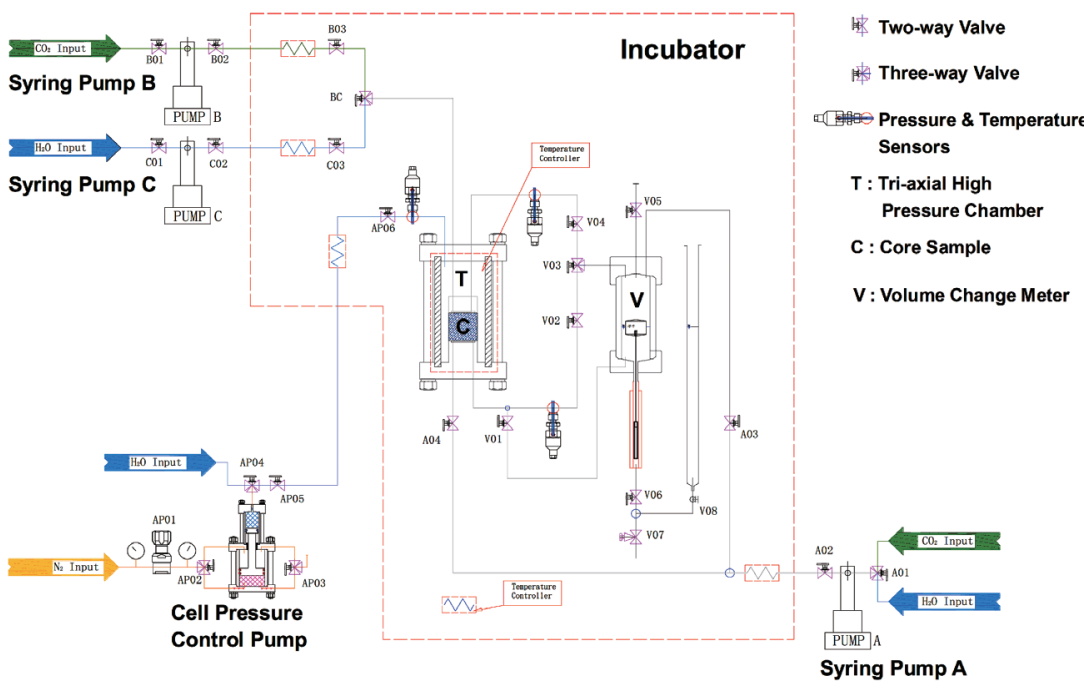

Fig. 4. Layout showing connecting of major elements of the test facility. The cell pressure is controlled by a Pneumatic pump with maximum capacity of $50 \mathrm{MPa}$. The 3 syringe pumps (TELEDYNE ISCO D260) are responsible for controlling the back pressure (pump A), super-critical CO ${ }_{2}$ injection (pump B), water injection (pump C) respectively. (Color online only)

in a $\mathrm{CO}_{2}$-brine system. Unfortunately, how capillary behavior inside the rock voids affects core flooding under a twophase laboratory environment remains uncertain and is only qualitatively known.

A typical two-phase flow involved in displacement fluid processes in a porous media is normally described as consisting of two cycles including the drainage displacement and imbibition displacement. In a drainage cycle, the super-critical phase $\mathrm{CO}_{2}$ is injected at a constant flow rate or constant differential pressure into a water-saturated core specimen by the displacement method under preset pressure $(P)$ and temperature $(T)$ conditions. Both the absolute permeability $\left(k_{a}\right)$ and relative permeability $\left(k_{r w}\right.$ and $\left.k_{r g}\right)$ can be obtained by the drainage test under different stages with the same $P-T$ condition. The subsequent imbibition process is also made possible in a reverse operation. In the case where the super-critical phase $\mathrm{CO}_{2}$ is injected at a constant flow rate, it should be noticed that the higher the rate, the higher the relative permeability is (e.g., Qadeer et al. 2002).

\subsection{Test Data}

The preset test condition used in each of the tests is shown in Table 1. The operation procedure has been standardized through a series of calibrating cores using purchased Berea Sandstone with a precisely known permeability $\left(k_{a}\right)$ in ranges of $100-300 \mathrm{mD}$ (mini-Darcy). To assure all the results are accurate, both reliability and validity tests have been implemented with Berea Sandstone prior to testing the field sample cores. Figure 5 shows the results of the reliability test using two identical sandstone core specimens.

The diameter of the testing core specimen is around 
Table 1. Preset test condition.

\begin{tabular}{|c|c|c|}
\hline Control Factors & Preset Values & Remarks \\
\hline Sample Height & $5 \mathrm{~cm}$ & NX size core \\
\hline Sample Diameter & $5 \mathrm{~cm}$ & NX size core \\
\hline Cell pressure & $13 \mathrm{MPa}$ & Pneumatic pump, 50 MPa max. \\
\hline Back pressure & $10 \mathrm{MPa}$ & ISCO D260 Syringe pump A \\
\hline $\mathrm{CO}_{2}$ injection & Constant flow & ISCO D260 Syringe pump B \\
\hline Water injection & Constant flow & ISCO D260 Syringe pump C \\
\hline Flow rate & 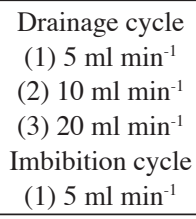 & $\begin{array}{l}\text { Drainage cycle } \\
\text { (1) } 5 \mathrm{ml} \mathrm{min} \text { mi }^{-1} \\
\text { (2) } 10 \mathrm{ml} \mathrm{min}^{-1} \\
\text { (3) } 20 \mathrm{ml} \mathrm{min}^{-1} \\
\text { Imbibition cycle } \\
\text { (1) } 5 \mathrm{ml} \mathrm{min} \text { m }^{-1}\end{array}$ \\
\hline Temperature & $40^{\circ} \mathrm{C}$ & $70^{\circ} \mathrm{C} \max$. \\
\hline
\end{tabular}
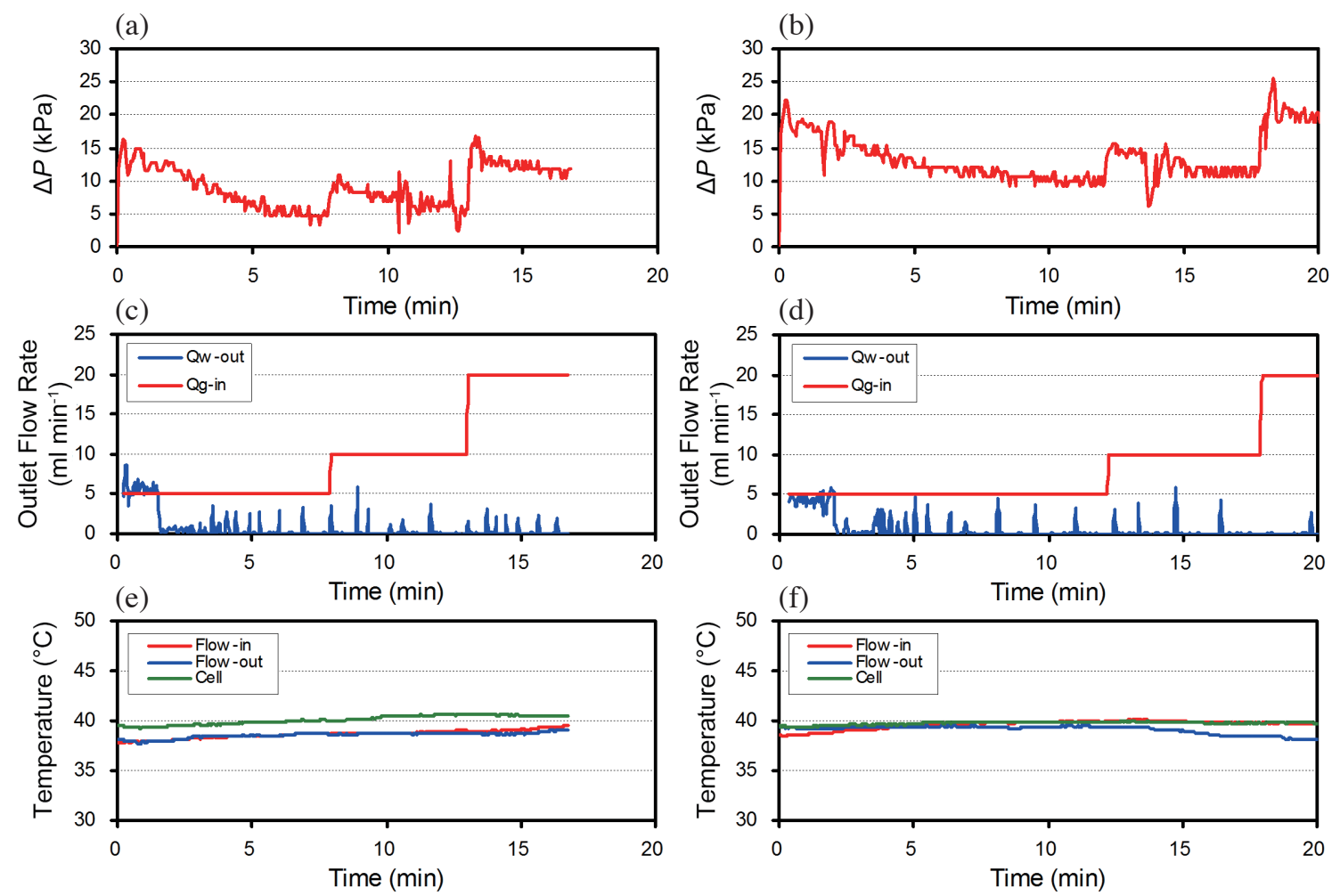

Fig. 5. Reliability check with two Berea sandstone samples: (a) differential pressure, core-1, (b) differential pressure, core-2, (c) flow control, core-1, (d) flow control, core-2, (e) temperature control, core-1, (f) temperature control, core-2.

$5 \mathrm{~cm}$ both for the Berea Sandstone and field sample cores. A constant flow rate control rather than a constant pressure control is adopted due to the fact that the maximum capacity of the volume meter to collect the displaced fluid is limited. During the test, the $5 \mathrm{~cm}$ high sample was wrapped properly with special lead-embedded membrane around the perimeter to ensure that the injected flow will go through the core assembly internally without leakage (see Fig. 6) or fluid bypassing around the core. After water saturation and consolidation, the temperatures in the incubator (maximum capacity $70^{\circ} \mathrm{C}$ ) and circulation thermostat were set constantly at $40^{\circ} \mathrm{C}$.

\subsection{Establish $K$ - $S$ Curve}

The purpose of the two-phase test is to generate the relationship between relative permeability (Corey 1954) and saturation, which has been often quoted as the $K-S$ curve. 


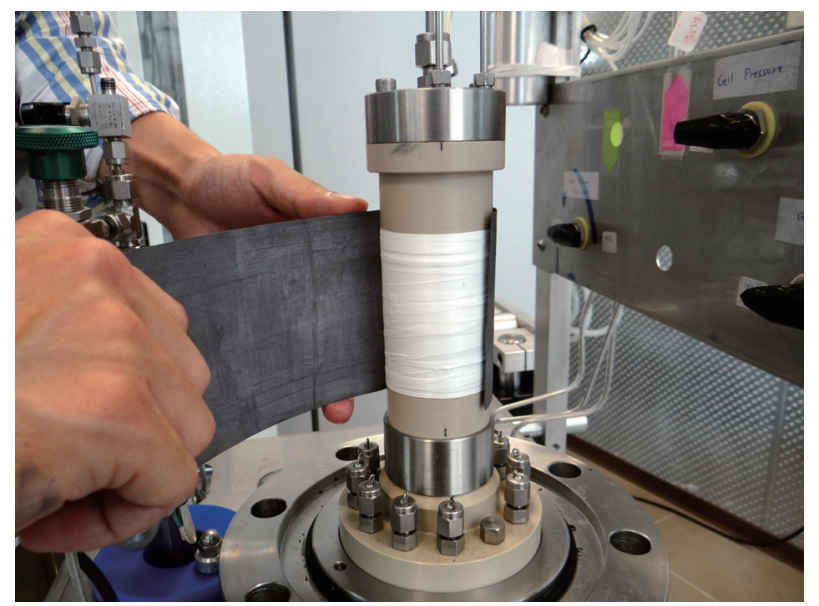

Fig. 6 . The rock core sample $(5 \mathrm{~cm}$ height) is wrapped properly with a special lead-embedded membrane around the perimeter to ensure the flow will go through the sample internally without leakage.

A widely used empirical formulation proposed by van Genuchten-Mualem ( $v G M$ ) (Mualem 1976; Van Genuchten 1980) is adopted for representing the test result due to the fact that it has been recommended as an essential input in the TOUGH2/ECO2N simulation code (Pruess 2005) when dealing with the geo-sequestration problem in a deep saline aquifer. The empirical formulation of $K-S$ curve as proposed by Pruess (2005) is shown below:

$\left\{\begin{array}{c}K_{r w}=\bar{S}^{0.5}\left[1-\left(1-\bar{S}^{1 / \lambda}\right)^{\lambda}\right]^{2} \\ K_{r g}=(1-\hat{S})^{2}\left(1-\hat{S}^{2}\right)\end{array}\right.$

$\bar{S}=\left(S_{w}-S_{w r}\right) /\left(1-S_{w r}\right)$

$\widehat{S}=\left(S_{w}-S_{w r}\right) /\left(1-S_{w r}-S_{g r}\right)$

The parameters $K_{r w}$ and $K_{r g}$ in Eq. (1) denote the relative permeability for water and relative permeability for gas, respectively. The parameter $S_{w}$ in Eqs. (2) and (3) denotes water saturation in an incurred transient state. Parameters $\bar{S}$ and $\hat{S}$ are calculation values. The $K-S$ curve can be defined by three parameters including $\lambda, S_{w r}$, and $S_{g r}$, where parameter $\lambda$ represents an exponent, parameter $S_{w r}$ represents the irreducible water saturation, and parameter $S_{g r}$ represents the irreducible gas saturation.

The results of the three sets of tests using the cores sampled from boreholes no. TP-04 and TH-04H are outlined in Table 2. Best-fitting parameters with the $v G M$ model to describe the relative permeability are also shown. All of the data can provide the required information to establish the relevant $K$-S curves as those shown in Fig. 7, respectively for the three sets of tests. Time-elapsed test results of Test-3 in the drainage cycle, including data of (a) differential pressure, (b) flow rate control, (c) two-phase volume change, and (d) gas saturation are shown in Fig. 8.

\section{INTERPRETATION}

It is not an easy task to interpret the test results to formulate a relevant $K-S$ curve to be adopted as the input parameters for a numerical simulation. One major reason is that during a two-phase test by the displacement method, the saturation states for both the water and gas under drainage or imbibition cycles were difficult to quantify with high precision, apart from the difficulty that an uncertain admixture amount of two components can happen during the flooding process. Methods which are currently used can be subdivided into two representative methods, the (1) Pseudo-Darcy Method, and (2) Modified JBN Method. These methods are regarded as rational approaches for interpreting the test data in this study despite the uncertainty in the two-phase mixture volume which are described below.

\subsection{Pseudo-Darcy Method}

This method is a rather straight forward approach by simply assuming the injected pressure is taken as the mean value of the input and output pressures measured on both ends of the core. Thereby, the calculation of permeability follows exactly the same theory as proposed by Darcy's Law. The saturation for both the water $\left(S_{w}\right)$ and gas $\left(S_{g}\right)$ can be defined as follows, respectively.

$$
\begin{gathered}
S_{g}=\frac{W_{o}}{L A \phi} \\
S_{w}=1-S_{g}
\end{gathered}
$$

$L, A$, and $\phi$ in Eq. (4) denote the specimen height, 
Table 2. Test interpretation results of $K-S$ curve using the $v G M$ Model.

\begin{tabular}{c|c|c|c|c|c|c|c}
\hline \multirow{2}{*}{ Test No. } & \multirow{2}{*}{ Hole No. } & \multirow{2}{*}{ Depth (m) } & \multirow{2}{*}{ Porosity (\%) } & \multirow{2}{*}{ Permeability $(\mathbf{m D})$} & \multicolumn{3}{|c}{ Fitting Parameters $(\boldsymbol{K}-\boldsymbol{S}$ Curve $)$} \\
\cline { 5 - 8 } & & & & & $\boldsymbol{\lambda}$ & $\boldsymbol{S}_{w r}$ & $\boldsymbol{S}_{\boldsymbol{g}}$ \\
\hline Test-1 & TP-04H* & 13.40 & 20.8 & 8.21 & 0.80 & 0.37 & 0.16 \\
Test-2 & TP-04 & 27.15 & 13 & 2.00 & 0.75 & 0.00 & 0.12 \\
Test-3 & TP-04H & 13.20 & 21.1 & 9.05 & 0.64 & 0.21 & 0.16 \\
\hline
\end{tabular}

Note: *: H denotes the core has been taken in parallel to the bedding attitude.

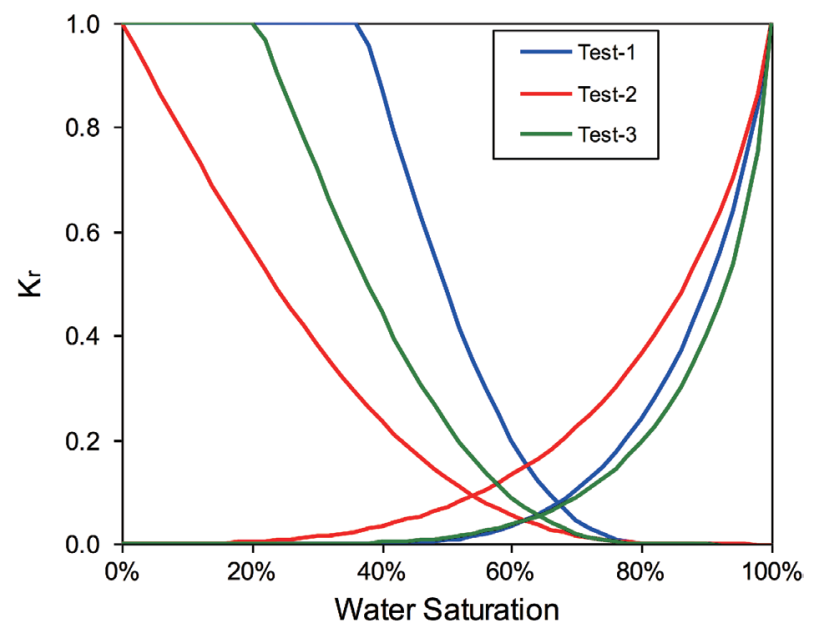

Fig. 7. Reconstruction of three $K-S$ curves tested. The interpreted test results are obtained using the $v G M$ model. Controlling parameters have been listed in Table 2. (Color online only)
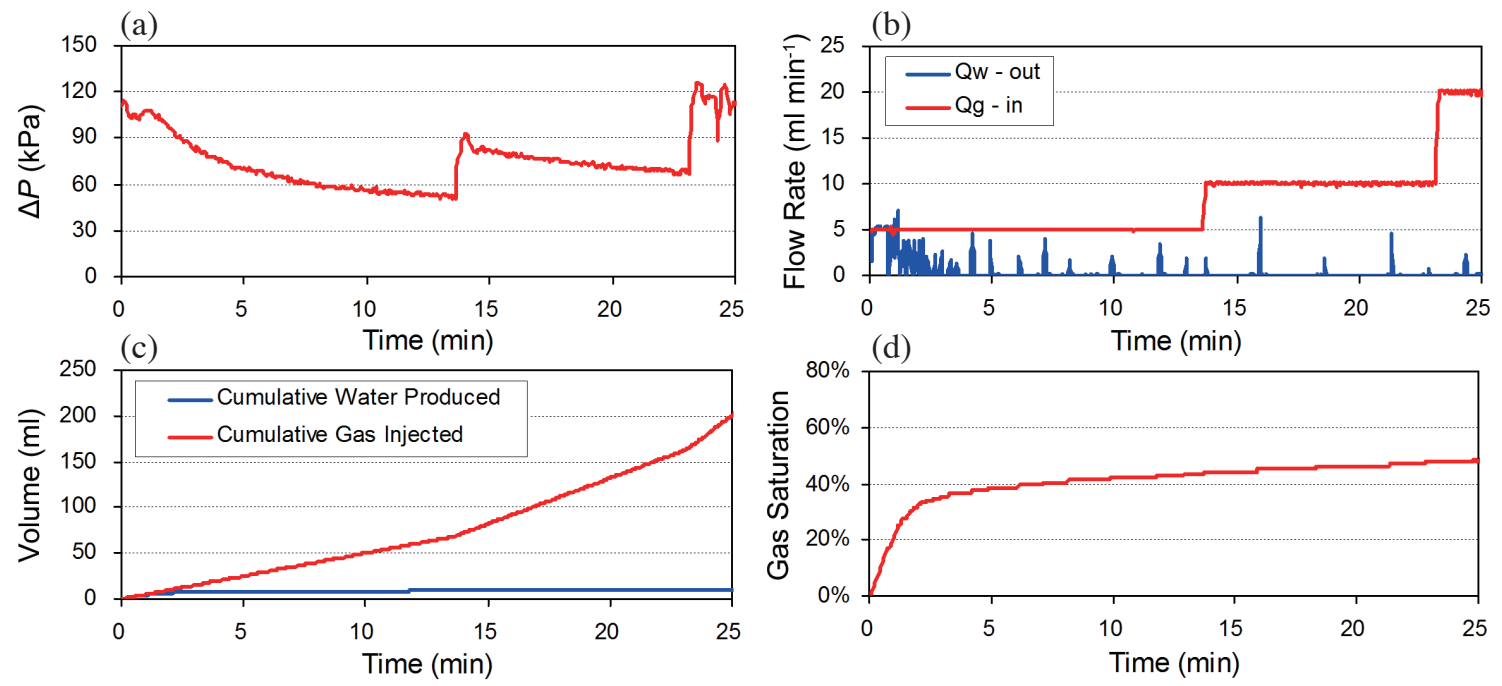

Fig. 8. Time-elapsed test results of Test-3 in the drainage cycle: (a) differential pressure, (b) flow rate control, (c) two-phase volume change, and (d) gas saturation. 
specimen cross-section area, and rock porosity, respectively. Multiplying the three values will be equal to the total void volume occupying the rock specimen, whereby $W_{o}$ denotes the cumulative water volume displaced. Parameter $S_{w}$ denotes the calculated water saturation as shown in Eq. (5). To generate the data points in a $K-S$ space, Eqs. (6) to (10) shown below can be used as a base for obtaining a relevant $K$-S Curve.

$k_{w}=\frac{\mu_{w} Q_{w} L}{A \Delta P}$, where $Q_{w}=\frac{d W_{o}}{d t}$

$k_{g}=\frac{\mu_{g} Q_{g} L}{A \Delta P}$, where $Q_{g}=\frac{d\left(G_{i}-W_{o}\right)}{d t}$

$k_{a b}=\frac{\mu_{w} L}{A}\left(Q_{w} / \Delta P\right)_{a b}$

$k_{r w}=\frac{k_{w}}{k_{a b}}=\frac{\left(Q_{w} / \Delta P\right)}{\left(Q_{w} / \Delta P\right)_{a b}}$

$k_{r g}=\frac{k_{g}}{k_{a b}}=\frac{\mu_{g}}{\mu_{w}} \frac{\left(Q_{g} / \Delta P\right)}{\left(Q_{w} / \Delta P\right)_{a b}}$

The parameters involved in the above equations and their corresponding meanings are denoted in Table 3 . Figure 9a shows the test data points in a $K-S$ space for Test-3 as an example. A sudden change in relative permeability when the water saturation value decreases below a value around $67 \%$ can be noted with regard to the $k_{r w}-S_{w}$ relationships. This sudden change may be explained as the gas break-through point in the drainage cycle of the core flooding test.

\subsection{Modified JBN Method}

In a relative permeability test using the displacement method, due to the fact that it is not applicable to measure fluid flow rate in the outlet core end directly, a separator for separately measuring the displaced liquid and gas phase volume is required. As a consequence, Johnson et al. (1959) proposed a relevant method that can be used to calculate the relative permeability from the displacement method where the pressure drop across the core and the cumulative fluid recovery of the displaced phase are known. This approach has been widely used by the oil industry and is generally called JBN method by commemorating the three authors who proposed the approach.

The conventional JBN method used Darcy's law and the Buckley-Leverett equation (Buckley and Leverett 1942) together and expanded the permeability ratio concept, which was originally suggested by Welge (1952). The JBN method has two basic assumptions, (1) the flow velocity is constant at all cross sections of the specimen, and (2) the flow velocity of fluids is sufficient to overcome capillary pressure. During the flowing process, the constant flow velocity is also assumed to ensure the fluid is incompressible. It has been noted that due to the capillary effect, the saturation in the displacing fluid phase will suddenly drop near the outlet. It has been referred as the head end effect. Hence, the pressure drop between both ends of the specimen must be large enough to assure a minimum saturation gradient so the capillary effect can be ignored. Based on the abovementioned assumptions and applied to this study, a Modified JBN Method is suggested in this study and could be partly rewritten as follows.

$f_{w}=\frac{d\left(S_{g}\right)_{a v}}{d\left(G_{i}\right)_{p v}}$, where $\left(S_{g}\right)_{a v}=\frac{W_{o}}{L A \phi} ;\left(G_{i}\right)_{p v}=\frac{G_{i}}{L A \phi}$

$f_{w}$ in Eq. (11) denotes the fraction of displaced phase in a flowing stream.

$k_{r w}=f_{w} \frac{d\left(1 / G_{i}\right)}{d\left(1 / G_{i} I_{r}\right)}$, where $I_{r}=\frac{(Q / \Delta P)}{(Q / \Delta P)_{\text {inital }}} ; Q=\frac{d G_{i}}{d t}$

$k_{r g}=\frac{1-f_{w}}{f_{w}} \frac{\mu_{g}}{\mu_{w}} k_{r w}$

The calculation process for obtaining water saturation $\left(S_{w}\right)$ and gas saturation $\left(S_{g}\right)$ resembles those already shown in Eqs. (4) and (5). Equations (11) to (13) illustrate the main control formula involved in the Modified JBN Method for generating a relevant data relationship in a $K-S$ space as long as the capillary end effect is negligible and the volumetric change of the gas is substantially small. The symbols and their corresponding meanings can be found in Table 3 .

It has been noted that direct substitution of the core injection testing data into Eq. (12) induced some difficulties and the results are not satisfactory. This is not only because the water outflow rate is too small but also the corresponding curve is not so smooth after a $\mathrm{CO}_{2}$ break-through in the specimen. Qadeer et al. (2002) proposed a sophisticated idea to enhance its practical application wherein they introduced displaced two-phase flow observation information obtained during the displacement test and improved pre-existing methods by reducing the unwanted signal in data processing. Qadeer et al. (2002) in their formulation expressed $W_{o}$ and $G_{i} I_{r}$ as a function of the $G_{i}$, and refined the signal by polynomial regression as shown respectively in Eqs. (14) and (15).

$W_{o}=a_{0}+a_{1}\left[\ln \left(G_{i}\right)\right]+a_{2}\left[\ln \left(G_{i}\right)\right]^{2}$

$\ln \left(G_{i} I_{r}\right)=b_{0}+b_{1}\left[\ln \left(G_{i}\right)\right]+b_{2}\left[\ln \left(G_{i}\right)\right]^{2}$ 
The authors integrated the smoothing algorithm by referencing the above work and put it into a spread-sheet calculation to enhance the efficiency of data processing. This method of data processing is hereby called a Modified JBN Method.

Using Test-3 as an example, the typical interpreted test results using Modified JBN Method are shown in Fig. 9b. It can be noted that the test data points in a $K-S$ space for the
Test-3, unlike the $k_{r w}-S_{w}$ relationship shown in Fig. 9a, are much smoother by contrast.

\section{HISTORY MATCHING}

It has been found that data interpretation using both above-mentioned methods fail to give satisfactory $K-S$ relationships, even though data points in the $K-S$ space using

Table 3. Contrast of symbol and its physical meaning.

\begin{tabular}{ccc}
\hline Symbol & Corresponding Item & Unit \\
\hline$S_{g}$ & Gas saturation & $\%$ \\
$S_{w}$ & Water saturation & $\%$ \\
$L$ & Specimen height & $\mathrm{m}$ \\
$A$ & Specimen cross section area & $\mathrm{m}^{2}$ \\
$\phi$ & Porocity & $\%$ \\
$Q$ & Flow rate & $\mathrm{m}^{3} \mathrm{~s}^{-1}$ \\
$Q_{w}$ & Water flow rate & $\mathrm{m}^{3} \mathrm{~s}^{-1}$ \\
$Q_{g}$ & Gas flow rate & $\mathrm{m}^{3} \mathrm{~s}^{-1}$ \\
$W_{o}$ & Cumulative water volume displaced & $\mathrm{m}^{3}$ \\
$k_{r w}$ & Relative permeability for water & $\%$ \\
$k_{r g}$ & Relative permeability for gas & $\%$ \\
$I_{r}$ & Relative Injectivity & - \\
$\mu_{g}$ & Gas viscosity & $\mathrm{Pa} \cdot \mathrm{S}$ \\
$\mu_{w}$ & Water viscosity & $\mathrm{Pa} \cdot \mathrm{S}$ \\
$K_{a}$ & Absolute permeability for gas & $\mathrm{m} \mathrm{sec}{ }^{-1}$ \\
$f_{w}$ & Slope of mean gas saturation to cumulative gas volume injected & - \\
$\left(S_{g}\right)_{a v}$ & Mean gas saturation & - \\
$\left(G_{i}\right)_{p v}$ & Cumulative gas volume injected normalized by pore volume & - \\
$G_{i}$ & Cumulative gas volume injected & $\mathrm{m}^{3}$ \\
$\Delta P$ & Differential pressure & $\mathrm{MPa}$ \\
\hline
\end{tabular}

(a)

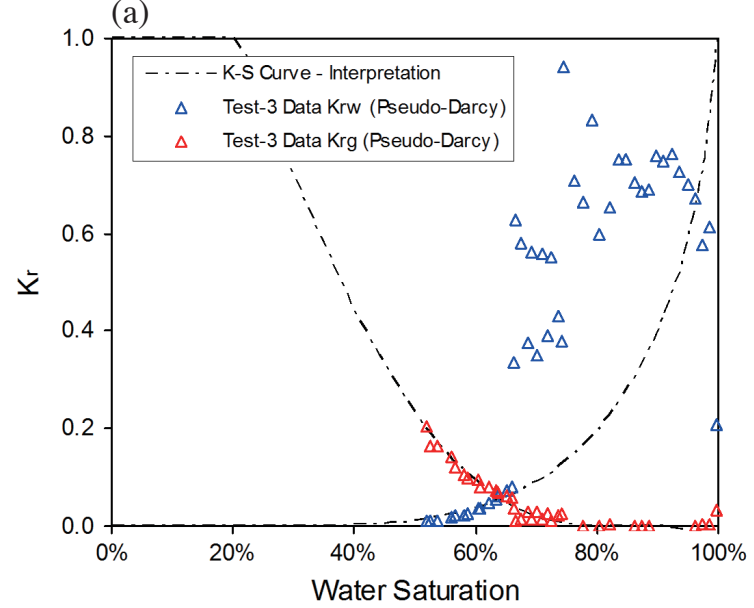

(b)

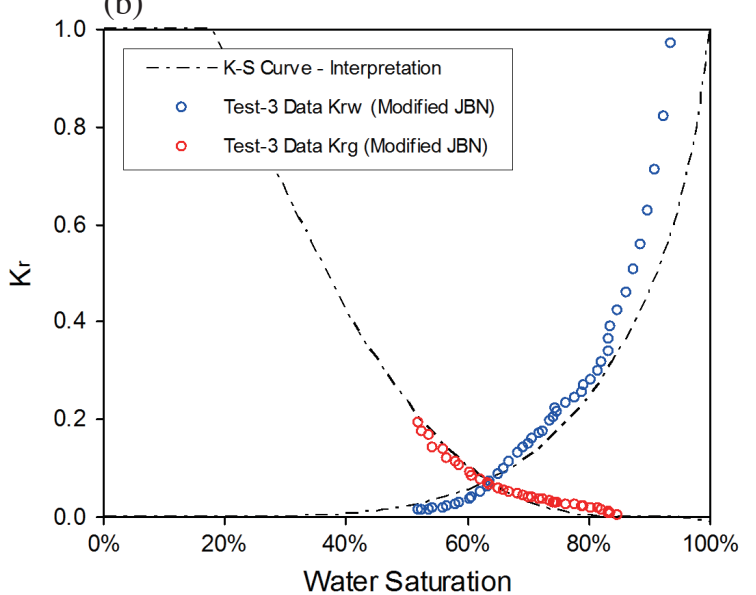

Fig. 9. Test results of Test-3 as interpreted by the two proposed methods, the (a) Pseudo-Darcy Method, and (b) Modified JBN Method. (Color online only) 
the Modified JBN Method looked apparently smoother than those of the Pseudo-Darcy Method. We should bear in mind that in a displacement test method, the injected $\mathrm{CO}_{2}$ in the drainage cycle will exhibit a piston-like movement and thus form a moving front. The gas break-through point will be found only when the fluid front leaves the outlet end of the specimen. This is clearly reflected in the test results using the Pseudo-Darcy Method. Those data points prior to the gas break-through point should not be used to generate the $K$-S Curve; otherwise, misleading results can occur and lead to an erroneous parameter calculation.

The history matching method has long been used to calculate the core scale of relative permeability from low rate displacement data (Qadeer et al. 2002; Horne et al. 2008; Krause et al. 2009, 2011; Suenaga and Nakagawa 2011; Kameya et al. 2011; Kuo et al. 2011). The relative permeability curves are examined in this method by a numerical iteration approach until a satisfactory match is reached between observed and calculated data. Thanks to the development of the TOUGH2/ECO2N simulation code (Pruess 2005), the simulation of a test process is becoming applicable using such a sophisticated simulator which allows for an inside view of the core-flooding process during a twophase flow test with the displacement method. In this study, a parallel version of the TOUGH2 code (TOUGH2-MP v2.0 by Zhang et al. 2008) has been used to carry out the relevant simulation work, including the test process simulation and a history matching of test processes. A history matching approach was adopted to rectify the test results by comparing against the simulated results. The general steps of the history matching approach are illustrated in Fig. 10. It is noted that the history matching method requires the use of capillary pressure data.

\subsection{The Capillary Pressure Effect}

It can be noted that the $P$-S curve (capillary pressure and saturation relationship) and related parameters have been incorporated simultaneously in the history matching process. As also proposed by Van Genuchten (1980), the $P-S$ curve can be established by the formulation shown below:

$P_{c}=-P_{0}\left(\bar{S}^{-1 / \lambda}-1\right)^{1-\lambda}$

$\bar{S}=\left(S_{w}-S_{w r}\right) /\left(1-S_{w r}\right)$

Where in Eq. (16), parameter $P_{0}$ denotes the strength factor, and parameter $\lambda$ is a shape factor, which defines the $P$ - $S$ curve. The parameter $S_{w r}$ represents the irreducible water saturation in Eq. (17) while parameters $S_{w}, \bar{S}$ and $\widehat{S}$ are intervening calculation values. Normally, the $P-S$ curve can be obtained from a mercury injection test using a porosimeter. The typical mercury injection test results showing the
$P$-S relationships for the cores sampled respectively from the four boreholes in the field outcrop are depicted in Fig. 11.

When $\mathrm{CO}_{2}$ is injected into the specimens and prior to break-through the specimen, the gas saturation distributions are not only affected by the entry pressure (also referred to as threshold pressure), but also by the capillary pressure. An increase in the injection rate may help increase the displaced water volume, reduce the head effect, and avoid overestimation of irreducible water saturation. The capillary effect can be tested using a history matching simulation. Table 4 and Fig. 12 show the $P-S$ curves of the three sets of matching results (Test-1, Test-2, and Test-3) compared with one test result using the mercury inject test (MIT). The curved shapes used in the history match resemble the core test results by MIT, but the order of magnitude is slightly lower. It should be noted that the $P-S$ curves of core test results by MIT used here are only a typical results among several tested samples. Best fit of the history matching curves to MIT results can be obtained if the best of strength factor $P_{0}$ is adopted (Lei et al. 2011).

\subsection{Relative Permeability}

The acquired test data, including mainly the differential pressure, outflow rate of displaced water or $\mathrm{CO}_{2}$, and the water or gas saturation can be used as ideal targets for history matching with respect to numerical output. Figure 13

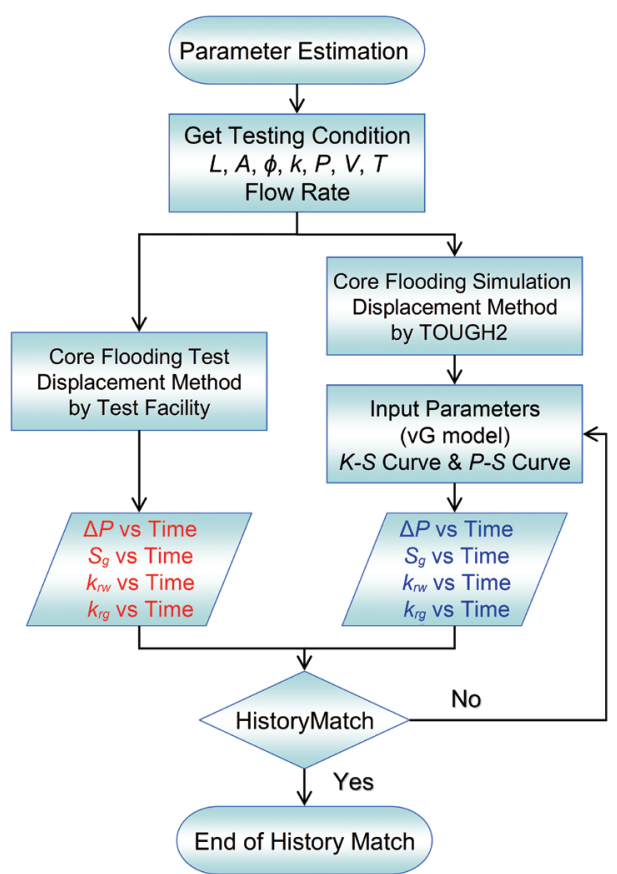

Fig. 10. General steps of the conceptual model in a history matching approach. The acquired testing data including differential pressure, outlet flow rate of displaced water or $\mathrm{CO}_{2}$, water or gas saturation can be used as ideal targets for history matching with a numerical output. (Color online only) 

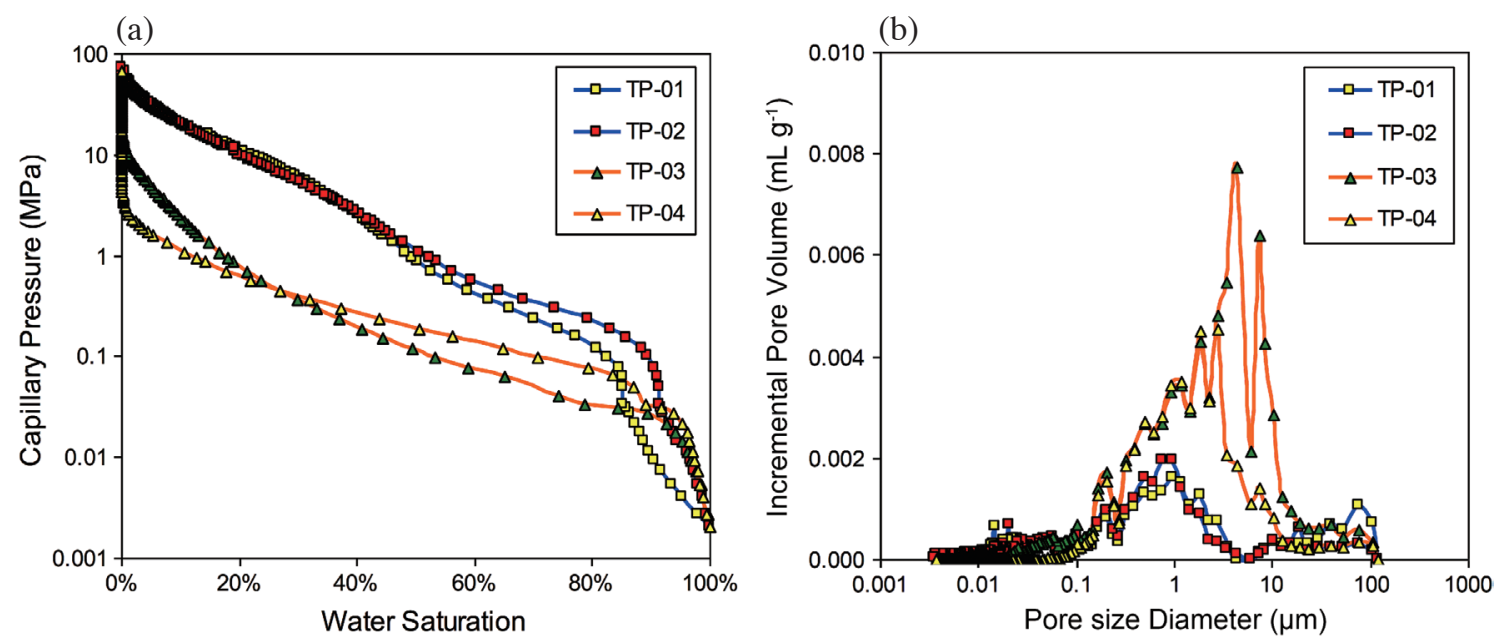

Fig. 11. Typical mercury injection test results for the cores sampled, respectively, from the four boreholes in the field outcrop showing (a) the $P$ - $S$ relationships and (b) the pore size distributions.

Table 4. Best fitting parameters of $P-S$ curve by the history matching approach.

\begin{tabular}{c|c|c|c|c}
\hline \multirow{2}{*}{ Fitting Method } & \multirow{2}{*}{ Target } & \multicolumn{3}{|c}{$\boldsymbol{P}$ - $\boldsymbol{S}$ Curve Parameters $(\boldsymbol{v} \boldsymbol{G}$ function*) } \\
\cline { 3 - 5 } & & $\boldsymbol{\lambda}$ & $\boldsymbol{S}_{\boldsymbol{w}}$ & $\boldsymbol{P}_{\mathbf{0}}(\mathbf{k P a})$ \\
\hline Test Interpretation & TP-04 specimen & 0.46 & 0 & 100 \\
\hline \multirow{3}{*}{ History Matching } & Test-1 & 0.46 & 0 & 6.7 \\
\cline { 2 - 5 } & Test-2 & 0.46 & 0 & 50 \\
\cline { 2 - 5 } & Test-3 & 0.46 & 0 & 28.6 \\
\hline
\end{tabular}

Note: * van Genuchten function (Van Genuchten 1980).

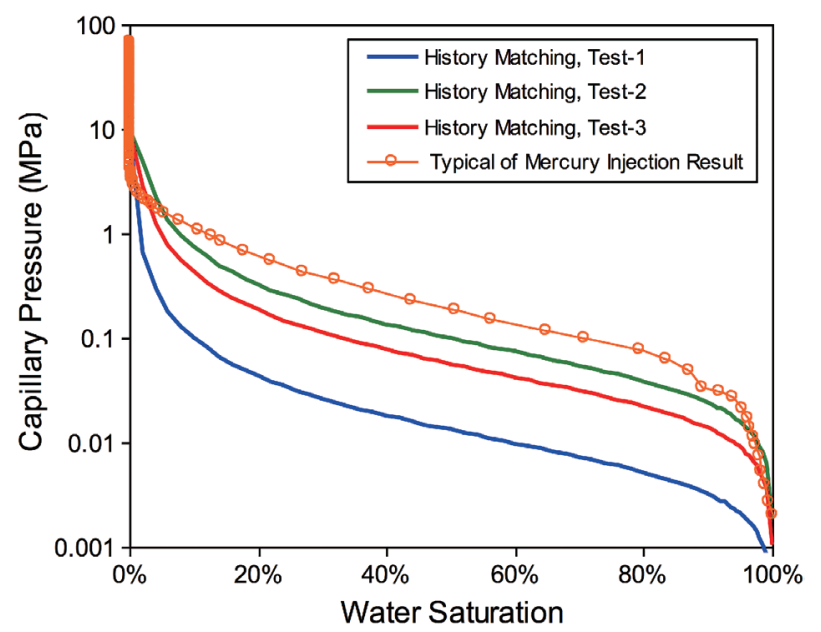

Fig. 12. Comparison of history matching $P$-S Curves with mercury injection test results. 

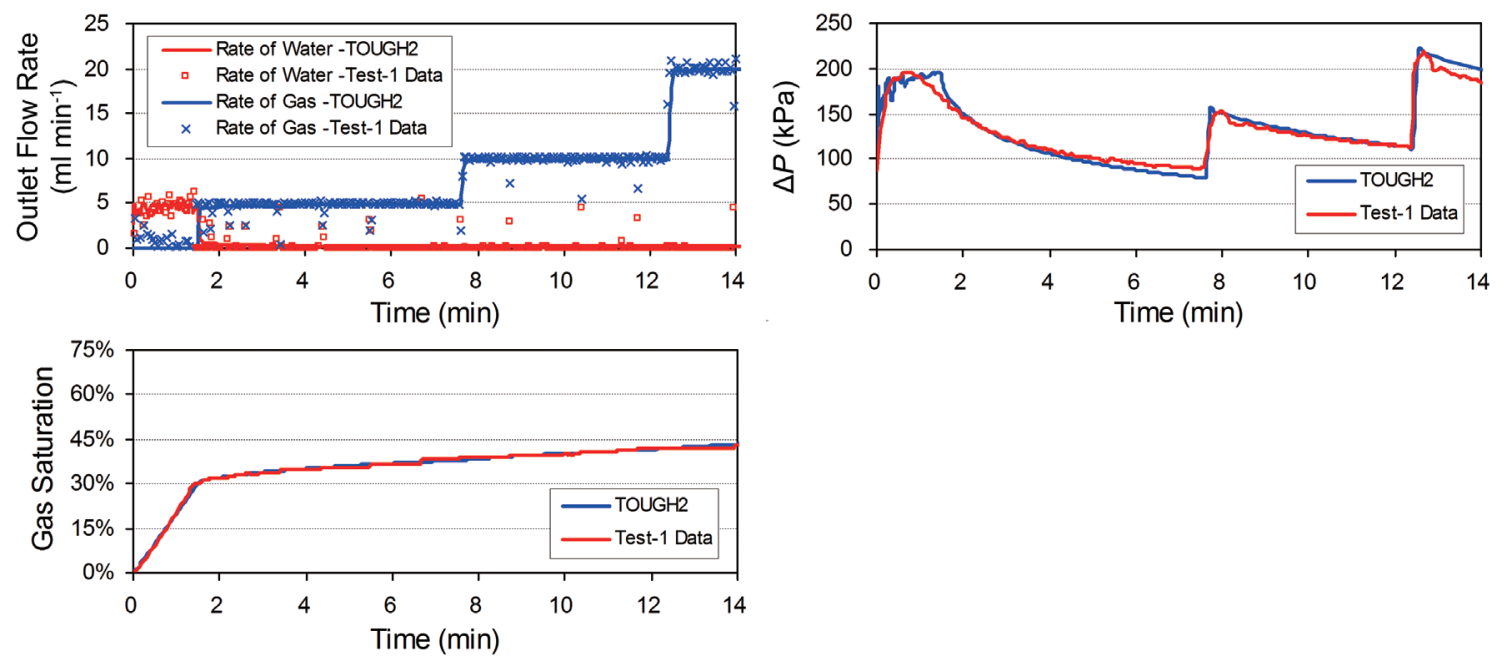

Fig. 13. Comparison of time-elapsed test data against the simulation data of Test-1.

shows the matching condition where controlling parameters of $v G M$ model were calibrated by a group of parameters controlling the capillary pressure. The calibrated data where a satisfactory match was obtained using Test-1 results as an example are listed in Table 5.

Figure 14 shows the comparisons of the $K$-S relationships using the test data of Test- 1 . The test data derived from test interpretation using both the Modified JBN and Pseudo-Darcy approaches are compared with the history matched $K$-S curves as constructed by the TOUGH 2 simulation process. The dashed lines in Fig. 14 denote the $K-S$ curves directly interpreted from test results while the calibrated $K$-S curves by the historical match method are shown by solid lines in the figure.

It has been noted that these test interpretations for Test1 can only be based on the results within the test range where the gas break-through point has been reached. Like those $K-S$ curves (dashed lines) schematically shown in Fig. 9 for Test-3, the high water saturation side beyond the gas break-through point denotes the initial stage of the drainage cycle where only the water phase is displaced like water flow inside a cylinder until reaching the outflow and the flooding process resembling a single phase behavior. The onset of a two-phase flow can be found only when the gas breakthrough point is reached. Hence, only the data on the low water saturation side beyond gas break-through point are regarded as meaningful results.

Apparently, there is still an intrinsic gap existing in between the experimentally observed and numerically calibrated data. The calibrated $K-S$ curves derived from the $v G M$ model parameters listed in Table 5 are incapable of fully matching the test data; and the test interpretation results tend to overestimate the relative permeability values as illustrated in Fig. 14. These non-negligible differences imply the apparent influences induced either by ignoring the capillary pressures, or resulting from approximating a transient state as a steady state in a displacement flooding process. As a consequence, however, it is important to know that in the interpretation of test data in a two-phase flow flooding process using the displacement method, the relationship with the selected capillary effect, e.g., $P-S$ curve, of the core sample should not be fully ignored.

\section{FIELD INJECTION PREDICTION}

With the basic calibrated parameters of $K-S$ and $P-S$ curves by laboratory testing, relevant field injection prediction can be performed to help in planning an upcoming pilot injection test program in a carbon sequestration project. Figures 15 and 16 show the field scenario analysis based on parameters by current history matching results (using the Test- 1 parameter sets as an example). These simulation results are regarded as a preliminary effort since a field test is not yet possible.

The $6 \mathrm{~km}$ square geological model for field injection prediction is constituted of a sandstone reservoir with a thickness of $150 \mathrm{~m}$ and a up lying cap rock with a thickness of $100 \mathrm{~m}$. The injection depth is approximately $2350 \mathrm{~m}$. The nearly flat reservoir stratum dips along a north-east azimuth with a dipping angle of 5 degree. Three monitoring wells surrounding the injection well are all at a distance of $50 \mathrm{~m}$. This arrangement is designed to observe the results of injected $\mathrm{CO}_{2}$. In this study, the injection rate for the scenario analysis is set at 20 tons per day in the early operation and increases to 40 tons per day after 120 days. The injection point is set at $5 \mathrm{~m}$ under the bottom of the cap rock; the injection operations last for one year. History matched parameter sets of Test- 1 have been adopted in the field injection prediction analysis to identify the degree of injection influences within the reservoir at preset permeability condition. 
Table 5. Best fitting parameters of $K-S$ curve by history matching approach for Test-1.

\begin{tabular}{c|c|c|c|c}
\hline \multirow{2}{*}{ Test Interpretation Method } & \multirow{2}{*}{ Fitting Method } & \multicolumn{4}{|c}{$\boldsymbol{K}$ - $\boldsymbol{S}$ Curve Parameters ( $\boldsymbol{v} \boldsymbol{G M}$ model*) } \\
\cline { 3 - 5 } & & $\boldsymbol{\lambda}$ & $\boldsymbol{S}_{\boldsymbol{w}}$ & $\boldsymbol{S}_{\boldsymbol{g}}$ \\
\hline \multirow{2}{*}{ Pseudo-Darcy } & Test Interpretation & 0.80 & 0.37 & 0.16 \\
\cline { 2 - 5 } & History Matching & 0.64 & 0.33 & 0.10 \\
\hline \multirow{2}{*}{ Modified JBN } & Test Interpretation & 0.88 & 0.37 & 0.14 \\
\cline { 2 - 5 } & History Matching & 0.65 & 0.34 & 0.10 \\
\hline
\end{tabular}

Note: * van Genuchten-Mualem model (Mualem 1976; Van Genuchten 1980).
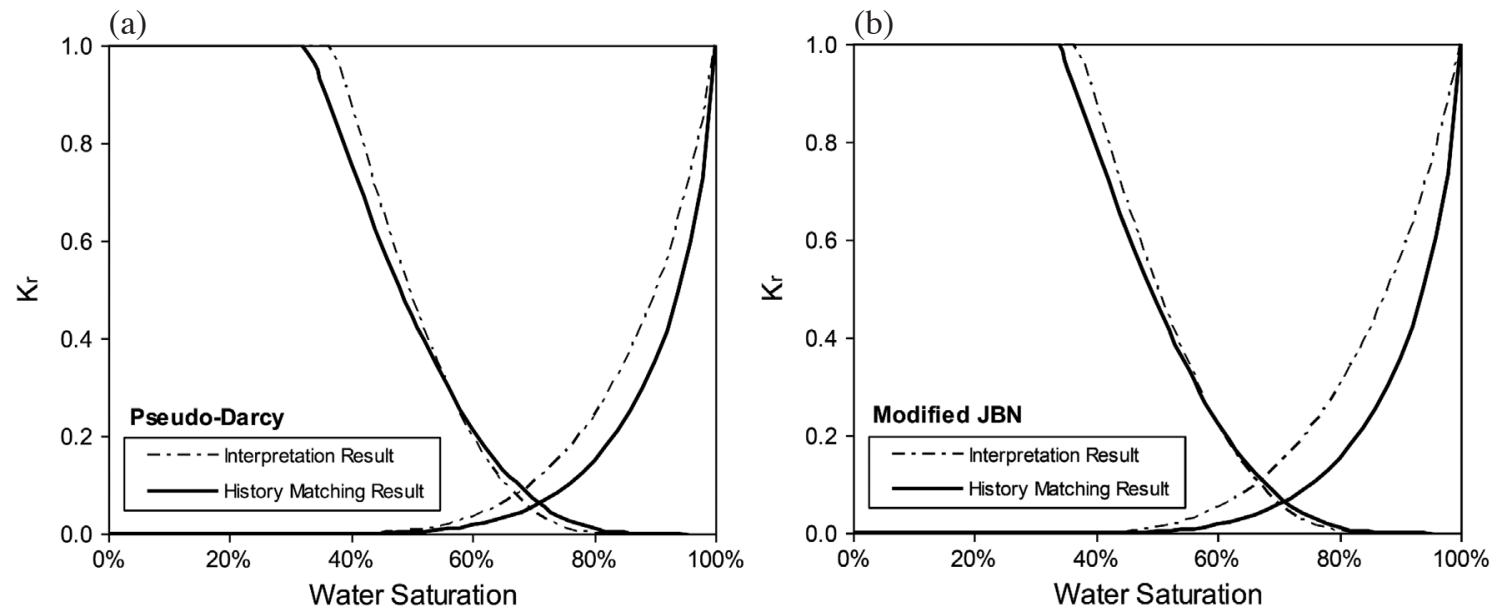

Fig. 14. Comparison of $K$-S curves between test interpretation results and history matching results of Test-1 using (a) the Pseudo-Darcy Method, and (b) the Modified JBN Method. The history matching data was predicted using the TOUGH2 simulator shown by the solid lines.

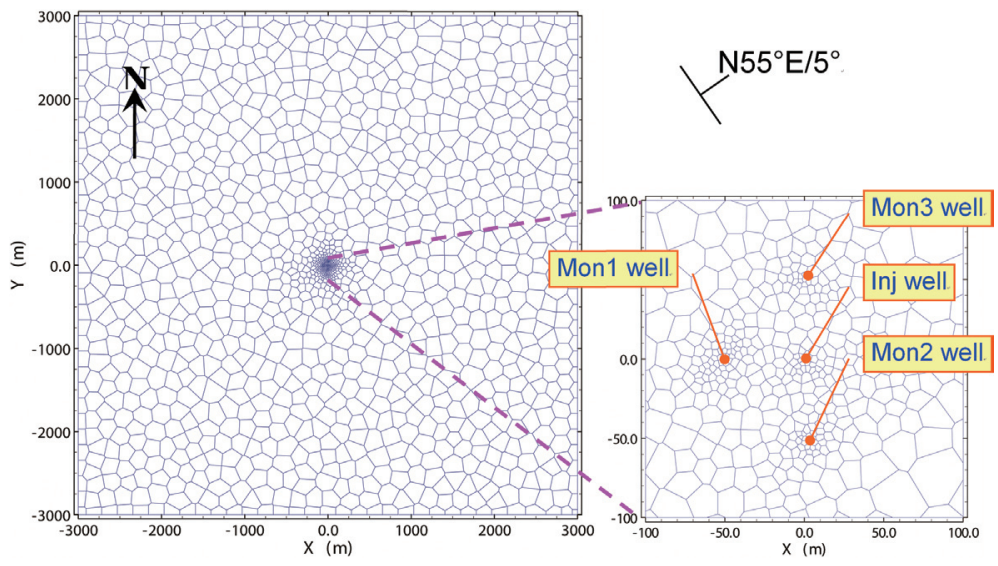

Fig. 15. The 2-D numerical mesh generation for field injection prediction. One injection well and three monitoring wells were installed. Three monitoring wells surrounding the injection well are all at a distance of $50 \mathrm{~m}$. 
(a)

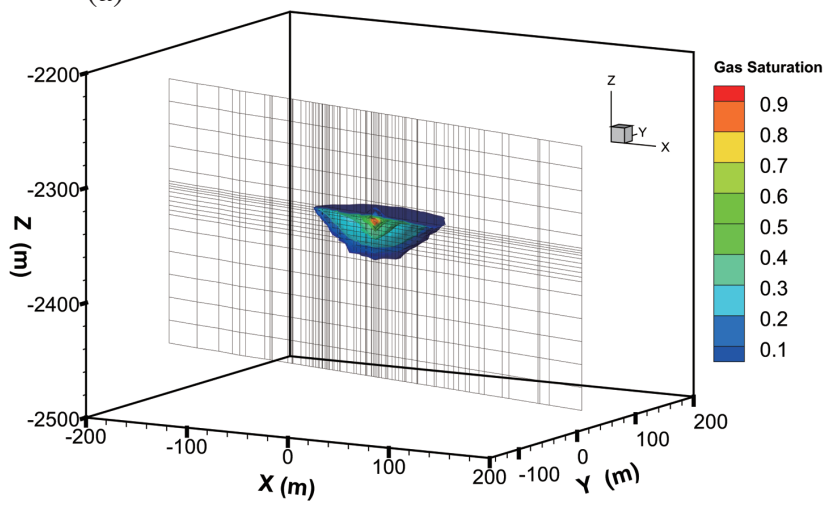

(b)

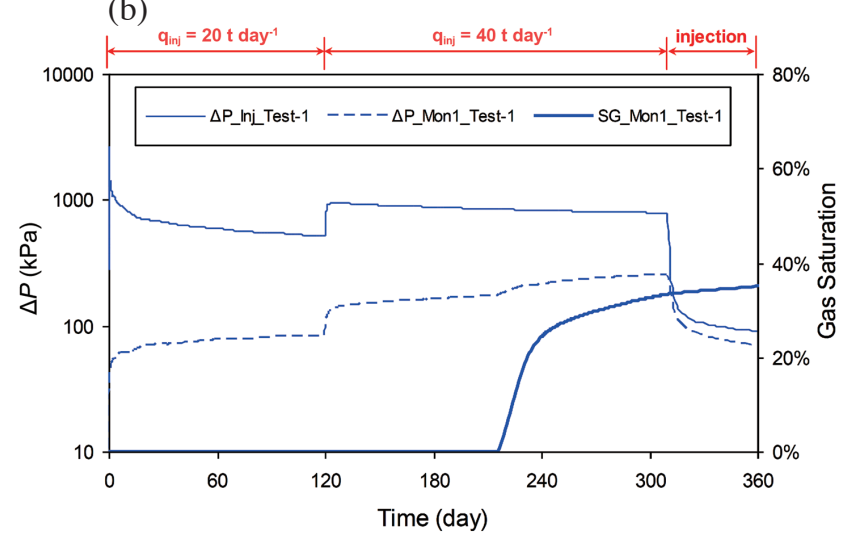

Fig. 16. Time-lapsed injection responses over a one year period, (a) the $\mathrm{CO}_{2}$ plume distribution within the reservoir in terms of gas saturation contour, and (b) the differential pressure of the injection well and monitoring well-1. Also shown is the super-critical $\mathrm{CO}_{2}$ arrival time as a function of gas saturation.

Figure 16a shows the result of injected $\mathrm{CO}_{2}$ where the plume colour contours represent the degree of $\mathrm{CO}_{2}$ gas saturation after the end of one-year injection operation. Figure $16 \mathrm{~b}$ indicates the time-lapsed responses, including (1) the differential pressure of the injection well and one of the monitoring wells, and (2) the super-critical $\mathrm{CO}_{2}$ arrival time. An observation point was installed at the bottom of a cap rock within each well. It is noted that the different pressure responses within the reservoir can be observed within injection well $\left(\Delta \mathrm{P} \_\right.$Inj_Test-1) and the monitoring wells $\left(\Delta \mathrm{P} \_M o n 1 \_\right.$Test-1) respectively. The $\mathrm{CO}_{2}$ gas saturation (SG_Mon1_Test-1) can also be obtained wherein the time of arrival of $\mathrm{CO}_{2}$ from injection well to a monitoring well can be predicted. The latter is particularly important for planning a pilot test.

Results of Fig. 16b have shown the importance of a $K$-S curve input for practical prediction of $\mathrm{CO}_{2}$ plume behavior simulation. Upon obtaining the monitoring data from a real field injection test, history matching approach should be exercised again to calibrate the input $K-S$ and $P-S$ curves, so long as the scaling effect of laboratory and field test is taken into account.

\section{CONCLUSION}

In this study, relevant $K$ - $S$ curves for porous sandstone cores sampled from a candidate reservoir rock have been obtained. The $K-S$ curves are regarded as critical input parameters controlling the feasibility of geo-sequestration in a deep saline aquifer.

A two-phase flow or core-flooding test process using the displacement method with constant flow injection has been successfully established with corresponding tests successfully carried out. Through the tests, a comprehensive study of the two-phase flow behavior for both the drainage and imbibition cycles in preset testing conditions has been conducted. It has been also shown that $K-S$ curves obtained directly from the test results in the drainage cycle can not reflect the two-flow phase behavior alone. Parallel considerations of the capillary pressure in the interpretation of the test results might also be necessary especially when the allowable injection flow is low.

Using the Pseudo-Darcy Method and Modified JBN Method to interpret the test data, we were able to model the parameters of relative permeability for predicting the movement of super-critical $\mathrm{CO}_{2}$ after injection into rock formations. However, to enhance their reliability and real-world applicability, the modeled parameters can be calibrated using history match processes. Hence, the iterative curve-fitting calibration on the time-elapsed test data should be exercised by back-analysis using the computer code TOUGH2.

This study establishes a conceptual model for conducting the history matching process to assist the interpretation of core-flooding test results, and to improve data reliability. The model is shown to be applicable if and only if the capillary effect is properly taken into consideration.

Moreover, a field injection prediction analysis has been implemented in the study and the significance of a $K-S$ curve input to a practical prediction of $\mathrm{CO}_{2}$ plume behaviour simulation is identified. Upon obtaining the monitoring data from real field injection test, history matching method should be exercised again to calibrate the input $K-S$ and $P-S$ curves, as far as the scaling effect of laboratory and field testing is taken into account.

Acknowledgements We would like to thank the Taiwan Power Company for full financial support in establishing the test facility to complete this study. The authors are indebted to many colleagues' contributions. Without their help, this paper could not be completed. Thanks are also extended to Dr. C. H. Tan for his assistance in preparing a geologic plan map. Mr. C. H. Tsai and Mr. C. H. Yang are gratefully 
acknowledged for their contributions in core preparation and conducting most of the tests.

\section{REFERENCES}

Bennion, B. and S. Bachu, 2005: Relative permeability characteristics for supercritical $\mathrm{CO}_{2}$ displacing water in a variety of potential sequestration zones. SPE Annual Technical Conference and Exhibition, SPE-95547MS, Dallas, Texas, Society of Petroleum Engineers, doi: 10.2118/95547-MS. [Link]

Bennion, D. B. and S. Bachu, 2006: The impact of interfacial tension and pore size distribution/capillary pressure character on $\mathrm{CO}_{2}$ relative permeability at reservoir conditions in $\mathrm{CO}_{2}$-brine systems. SPE/DOE Symposium on Improved Oil Recovery, SPE-99325-MS, Tulsa, Oklahoma, USA, Society of Petroleum Engineers, doi: 10.2118/99325-MS. [Link]

Benson, S. M., L. Tomutsa, D. Silin, T. Kneafsey, and L. Miljkovic, 2005: Core scale and pore scale studies of carbon dioxide migration in saline formations. Proceedings of $8^{\text {th }}$ International Conference on Greenhouse Gas Control Technologies, IEA Greenhouse Gas Program (GHGT8), Trondheim, Norway, June 19-22.

Buckley, S. E. and M. C. Leverett, 1942: Mechanism of fluid displacement in sands. Trans. AIME, 146, 107-116, doi: 10.2118/942107-G. [Link]

Corey, A. T., 1954: The interrelations between gas and oil relative permeabilities. Producers Mon., 19, 38-41.

Horne, R. N., R. Stacey, and K. Li, 2008: Physical modeling of Carbon Dioxide (CO2) sequestration. California Energy Commission, PIER: Public Interest Energy Research, CEC-500-2007-113, 31 pp.

IPCC, 2005: IPCC Special Report on Carbon Dioxide Capture and Storage, Prepared by Working Group III of the Intergovernmental Panel on Climate Change, Cambridge University Press, Cambridge, United Kingdom and New York, NY, USA, 442 pp.

Johnson, E. F., D. P. Bossler, and V. O. N. Bossler, 1959: Calculation of relative permeability from displacement experiments. Trans. AIME, 216, 370-372.

Kameya, H., K. Hosoda, J. Takeshima, H. Azuma, and S. Hiramatsu, 2011: Relative permeability experiments by displacement method for estimating $\mathrm{CO}_{2}$ movement. The $17^{\text {th }}$ Formation Evaluation Symposium of Japan, September 29-30, 2011.

Krause, M., J. C. Perrin, C. W. Kuo, and S. M. Benson, 2009: Characterization of $\mathrm{CO}_{2}$ storage properties using core analysis techniques and thin section data. Energy Procedia, 1, 2969-2974, doi: 10.1016/j.egypro.2009.02.073. [Link]

Krause, M., J. C. Perrin, and S. Benson, 2011: Recent progress in predicting permeability distributions for history matching core flooding experiments. Energy Proce- dia, 4, 4354-4361, doi: 10.1016/j.egypro.2011.02.387. [Link]

Kuo, C. W., J. C. Perrin, and S. M. Benson, 2011: Simulation studies of effect of flow rate and small scale heterogeneity on multiphase flow of $\mathrm{CO}_{2}$ and brine. Energy Procedia, 4, 4516-4523, doi: 10.1016/j.egypro.2011.02.408. [Link]

Lei, S. C., C. H. Yang, C. W. Yu, C. H. Chiao, L. T. Hwang, and C. R. Lan, 2011: Comparison of method of result analysis between steady-state method and displacement method in the two-phase flow testing. Conference on Resources Engineering, National Cheng Kung University Tainan, Taiwan, July 21-22, B, 16-21.

Lin, A. T., A. B. Watts, and S. P. Hesselbo, 2003: Cenozoic stratigraphy and subsidence history of the South China Sea margin in the Taiwan region. Basin Res., 15, 453478, doi: 10.1046/j.1365-2117.2003.00215.x. [Link]

Mualem, Y., 1976: A new model for predicting the hydraulic conductivity of unsaturated porous media. Water Resour. Res., 12, 513-522, doi: 10.1029/ WR012i003p00513. [Link]

Perrin, J. C., M. Krause, C. W. Kuo, L. Miljkovic, E. Charoba, and S. M. Benson, 2009: Core-scale experimental study of relative permeability properties of $\mathrm{CO}_{2}$ and brine in reservoir rocks. Energy Procedia, 1, 35153522, doi: 10.1016/j.egypro.2009.02.144. [Link]

Perrin, J. C., R. W. Falta, S. Krevor, L. Zuo, K. Ellison, and S. M. Benson, 2011: Laboratory experiments on corescale behavior of $\mathrm{CO}_{2}$ exolved from $\mathrm{CO}_{2}$-saturated brine. Energy Procedia, 4, 3210-3215, doi: 10.1016/j. egypro.2011.02.237. [Link]

Pruess, K., 2005: ECO2N: A TOUGH2 fluid property module for mixtures of water, $\mathrm{NaCl}$, and $\mathrm{CO}_{2}$. Report LBNL-57952, Lawrence Berkeley National Laboratory, Berkeley, CA.

Qadeer, S., W. E. Brigham, and L. M. Castanier, 2002: Techniques to handle limitations in dynamic relative permeability measurements. Topical Report, SUPRI TR 128, No. DOE/BC/15311-10, National Petroleum Technology Office, Tulsa, OK, USA.

Silin, D., T. Patzek, and S. M. Benson, 2009: A model of buoyancy-driven two-phase countercurrent fluid flow. Transport Porous Med., 76, 449-469, doi: 10.1007/ s11242-008-9257-1. [Link]

Suenaga, H. and K. Nakagawa, 2011: Analysis of two-phase flow properties of sandstones to evaluate their suitability for geologic storage of $\mathrm{CO}_{2}$. Energy Procedia, 4, 4323-4330, doi: 10.1016/j.egypro.2011.02.383. [Link]

Teng, L. S. and A. T. Lin, 2004: Cenozoic tectonics of the China continental margin: Insights from Taiwan. Geol. Soc. Lond. Spec. Publ., 226, 313-332, doi: 10.1144/ GSL.SP.2004.226.01.17. [Link]

Toth, J., T. Bodi, P. Szucs, and F. Civan, 2001: Direct determination of relative permeability from 
nonsteady-state constant pressure and rate displacements. SPE Production and Operations Symposium, SPE-67318-MS, Oklahoma, Society of Petroleum Engineers, doi: 10.2118/67318-MS. [Link]

Van Genuchten, M. Th., 1980: A closed-form equation for predicting the hydraulic conductivity of unsaturated soils. Soil Sci. Soc. Am. J., 44, 892-898, doi: 10.2136/s ssaj1980.03615995004400050002x. [Link]

Welge, H. J., 1952: A simplified method for computing oil recovery by gas or water drive. J. Petrol. Technol., 4,
91-98, doi: 10.2118/124-G. [Link]

Yu, C. W., S. Chen, K. S. Shao, C. H. Chiao, L. T. Hwang, and J. L. Chen, 2011: Development of CCS technology for coal-fired power plant in Taiwan. Energy Procedia, 4, 4806-4813, doi: 10.1016/j.egypro.2011.02.446. [Link]

Zhang, K., Y. S. Wu, and K. Pruess, 2008: User's guide for TOUGH2-MP - A massively parallel version of the TOUGH2 code. Report LBNL-315E, Lawrence Berkeley National Laboratory, Berkeley, CA. 